\title{
Long pentraxin 3: A marker of inflammation in untreated psoriatic patients
}

\author{
VALENTINA BEVELACQUA ${ }^{1,2 *}$, MASSIMO LIBRA $^{2 *}$, MARIA C. MAZZARINO $^{2}$, \\ PIETRO GANGEMI $^{3}$, GIUSEPPINA NICOTRA ${ }^{4}$, SALVATORE CURATOLO ${ }^{1}$, \\ DANIELA MASSIMINO ${ }^{1}$, ANTONIO PLUMARI ${ }^{1}$, PAOLA MERITO ${ }^{2}$, GUIDO VALENTE ${ }^{5}$, \\ FRANCA STIVALA ${ }^{2}$, STEFANO LA GRECA ${ }^{1}$ and GRAZIA MALAPONTE ${ }^{2}$
}

\author{
${ }^{1}$ Dermathology Unit, AORNAS, Garibaldi Hospital; ${ }^{2}$ Department of Biomedical Sciences, University of Catania; \\ ${ }^{3}$ Division of Pathology, Vittorio Emanuele Hospital, Catania; ${ }^{4}$ Molecular Pathology Laboratory, \\ Department of Medical Sciences, Amedeo Avogadro, University of Eastern Piedmont; ${ }^{5}$ Department of Clinical \\ and Experimental Medicine, Amedeo Avogadro, University of Eastern Piedmont, Novara, Italy
}

Received March 31, 2006; Accepted May 5, 2006

\begin{abstract}
Psoriasis is a common cutaneous disorder characterized by abnormal epidermal differentiation, proliferation and inflammation mediated by dermal infiltrates, such as T cells, neutrophils, dendritic cells and macrophages. There are renewed interest in the role of components of the innate immune system. Cytokines such as tumor necrosis factor- $\alpha$ (TNF- $\alpha$ ) and interleukin (IL)- 6 , and $-1 \beta$ involved in pathogenic phenomena in psoriasis are known as inducers of the acute phase response. Among the large group of acute phase reactants, C-reactive protein (CRP) and fibrinogen are of special interest in psoriasis. The PTX-3, a long pentraxin sharing similarities with the classical short proteins. Thus, considering the numerous biological roles of inflammatory cytokines and their relationship with inflammatory markers, such as CRP and fibrinogen we have investigated the role of PTX3 in psoriasis. To this aim PTX3, TNF- $\alpha$, IL-6 and IL-1ß in plasma and in monocytic cultures by enzyme linked immunosorbent assay (ELISA) in 44 patients including severe and mild psoriasis were measured. An increased production of PTX3, both in supernatant of purified monocytes and in plasma from patients with severe psoriasis, was found. The significant correlation, between cellular production and plasma levels of PTX3 in psoriasis was found as a sign of cellular activation by monocytes/macrophages that first infiltrate the psoriatic lesion. In severe psoriasis, a significant correlation between psoriasis area and severity
\end{abstract}

Correspondence to: Dr Grazia Malaponte, Department of Biomedical Sciences, University of Catania, Via Androne 83, 95124 Catania, Italy

E-mail: g.malaponte@unict.it

${ }^{*}$ Contributed equally

Key words: psoriasis, PTX3, cytokines index (PASI) score and TNF- $\alpha$ and IL-6 levels in both supernatant of monocytes and plasma was found. In contrast, no correlation was found for IL-1ß. By immunohistochemistry and immunofluorescence, a strong PTX3 staining in fibroblasts, endothelial cells and monocytes/macrophages in severe psoriatic lesional skin was detected. Finally, a positive correlation between PTX3 and disease activity of psoriasis was observed as PASI score was elevated. These findings suggest that PTX3 could be used as a further marker of disease activity of psoriasis.

\section{Introduction}

Psoriasis is a common cutaneous disorder characterized by abnormal epidermal differentiation, proliferation and inflammation mediated by dermal infiltrates, such as T cells, neutrophils, dendritic cells and macrophages (1). In recent years, important information has been provided by studies addressing the immunopathogenic mechanisms of the disease $(2,3)$. Multiple factors contribute to the initiation of psoriasis. They include specific genetic factors such as alleles from the major histocompatibility complex and various trigger factors, such as stress and infections (4-9). Psoriasis is considered as a mediated autoimmune disease caused by dysregulation of innate and adaptive immunity $(10,11)$. There is renewed interest in the role of components of the innate immune system. However, it may be that the overlap between the innate and acquired arms of the immune system can better explain immunopathogenesis in psoriasis (12). Inflammatory cytokines, such as tumor necrosis factor- $\alpha$ (TNF- $\alpha$ ), interleukin (IL)-1ß and IL-6, expressed in psoriatic patients, of the innate immune system initiate a cascade that activates inflammation locally in the skin and in the circulation $(13,14)$.

Some of the cytokines involved in pathogenic phenomena in psoriasis are known as inducers of the acute phase response. Among the large group of acute phase reactants, $\mathrm{C}$ reactive protein (CRP) and fibrinogen may be of special interest in psoriasis, given their relationship with inflammatory cytokines involved in the development of skin inflammation 
Table I. Patient characteristics with psoriasis vulgaris.

\begin{tabular}{|c|c|c|c|c|c|}
\hline & $\begin{array}{c}\text { Healthy } \\
\text { controls (C) }\end{array}$ & $\begin{array}{c}\text { mild } \\
\text { Psoriasis }(\mathrm{mP})\end{array}$ & $\begin{array}{c}\mathrm{P} \text {-value } \\
\mathrm{mP} \text { versus } \mathrm{C}\end{array}$ & $\begin{array}{c}\text { severe } \\
\text { Psoriasis }(\mathrm{sP})\end{array}$ & $\begin{array}{c}\mathrm{P} \text {-value } \\
\mathrm{mP} \text { versus sP }\end{array}$ \\
\hline Subjects & 25 & 18 & - & 26 & - \\
\hline Age $\left(\right.$ years) ${ }^{\mathrm{a}}$ & $40 \pm 12.74$ & $36.22 \pm 8.71$ & NS & $45.85 \pm 8.05$ & NS \\
\hline Male/female ${ }^{\mathrm{b}}$ & $14 / 11$ & $10 / 8$ & NS & $16 / 10$ & NS \\
\hline Psoriasis diseases & - & - & - & - & - \\
\hline Arthritis psoriasis & - & 5 & & 10 & - \\
\hline
\end{tabular}

aP-value was calculated by Wilcoxon test; ${ }^{\mathrm{P}} \mathrm{P}$-value was calculated by Chi-square test. Age is expressed as mean \pm standard deviation; NS, not significant.

(15). Several distinct larger proteins have been identified including 'the long pentraxins' (16). The PTX-3, a long pentraxin sharing similarities with the classical short proteins [CRP and serum amyloid P component (SAP)] but differs in the presence of an unrelated long $\mathrm{N}$-terminal domain coupled to the C-terminal pentraxin domain, for gene organization, chromosomal localization (chromosome 3q25) and cellular source (17). PTX-3 is produced at sites of inflammation by several types of cells, primarily by dendritic cells, macrophages, fibroblasts, activated endothelia, and by other tissues; its production is induced by inflammatory mediators such as lipopolysaccaride (LPS), IL- $1 \beta$ and TNF- $\alpha$, but not IL-6 $(18,19)$. In contrast, the classical short pentraxins (CRP and SAP) are produced only by hepatocytes in response to inflammatory cytokines, in particular IL-6 and IL-1 $(20,21)$. In fact, various inflammatory diseases impair CRP and fibrinogen production (22-26).

In humans, PTX3 levels are detectable during severe infections, autoimmune, and degenerative conditions, as rheumatoid arthritis (RA), systemic scleroderma (SSc) and small vessel vasculitis (27-29). PTX3 plays an important role in innate resistance against selected pathogens, in female fertility, in the regulation of inflammatory reactions, and possibly in autoimmunity (18).

Thus, considering the numerous biological roles of inflammatory cytokines and their relationship with inflammatory markers (CRP, fibrinogen) (29) and given similarities and differences between PTX3 and CRP, it is important to assess the usefulness of PTX3 as a novel diagnostic tool, which may better reflect the involvement of tissue in inflammatory processes.

The aim of this study was to analyze PTX3 levels in both plasma and supernatant of purified monocytes of patients with mild and severe psoriasis. PTX3 was also correlated with worsening of the disease, CRP, fibrinogen and proinflammatory cytokines (TNF- $\alpha$, IL-6, IL-1ß).

\section{Materials and methods}

Subjects. A total of 44 patients with psoriasis vulgaris (27 males, 17 females), mean age 42.2 \pm 9.4 (range: 23-58) years, were enrolled in this study. The patients were divided in two groups: 26 patients with severe psoriasis (age range: 36-58) and 18 with mild psoriasis (age range: $23-46$ years). The demographic and clinical characteristics are presented in Table I. Clinical evaluation of disease severity, expressed as the psoriasis area and severity index (PASI), was performed before the introduction of antipsoriatic treatment. The average PASI score in psoriatic patients was (range 3-33.4). None of the patients had received any local or systemic treatment before the collection of the blood samples. The control group consisted of 25 age- and sex-matched healthy individuals. Neither patients nor controls had a history of clinical or routine laboratory findings consistent with, impaired hepatic or renal function, nor parasitic or any other infection. All subjects signed an informed consent form.

Cell isolation, culture and stimulation of monocytes. Blood with anticoagulant, ethylenediamine tetraacetic acid (EDTA) was collected into pyrogen-free tubes from patients with psoriasis vulgaris and healthy subjects. Peripheral blood mononuclear cells were isolated as described by Böyum (30). Monocytes were prepared by centrifugation at $500 \mathrm{~g}$ for $30 \mathrm{~min}$ at room temperature on an isosmotic solution of $46 \%$ Percoll (Pharmacia, Uppsala, Sweden). The purity of monocytes was analysed on a FACScan flow cytometer (Becton Dickinson, Milan, Italy) with monoclonal antibodies CD14 and CD11c/ CD18 (Becton Dickinson). The estimated purity was $~ 95 \%$, and $>90 \%$ of monocytes were positive for non-specific acid esterase activity. Cell viability was estimated, by the trypan blue exclusion test, to be $\sim 95 \%$. Monocytes were incubated for $20 \mathrm{~h}$ at $37^{\circ} \mathrm{C}$ in $5 \% \mathrm{CO}_{2} 95 \%$ air atmosphere, in hydrophobic Petriperm dishes (Heraeus, Hanau, Germany). They were cultured without stimulus for evaluation of the spontaneous production of PTX3 and proinflammatory cytokines. The supernatant was collected after a $20 \mathrm{~h}$ incubation and put through a filter with $0.2 \mathrm{~nm}$ pores (Sigma Chemical Co., St. Louis, USA) and stored at $-80^{\circ} \mathrm{C}$ prior to analysis of PTX3 and cytokines. All reagents used were LPSfree, as determined by the Limulus amoebocyte lysate (LAL) assay (Kabi vitrum, Munich, Germany).

Preparation of blood samples. Blood was collected into pyrogen-free tubes with and without anticoagulant, EDTA and centrifuged within $30 \mathrm{~min}$ after collection to obtain plasma and serum. Subsequentily, the plasma and serum 
were stored at $-80^{\circ} \mathrm{C}$ until further evaluation. The plasma was used for the evaluation of fibrinogen, PTX-3 and IL-6, IL-1,TNF- $\alpha$ cytokines, the serum for CRP.

Markers of inflammation: acute phase protein. Serum CRP was evaluated by nephelometry (N High sensitivity CRP; Dade Behring). To evaluate the plasma levels of fibrinogen we used a turbidimetric assay (DiaMed, Morat, Switzerland).

Immunohistochemistry. Formalin-fixed paraffin-embedded tissue sections were cut from cutaneous biopsies. Sections were mounted on glass slides, deparaffinized in xylene, rehydrated in graded alcohol and finally washed in water. Prior to incubation with antibodies, the sections were subjected to a heat-induced antigen-demasking reaction. Immunohistochemistry was performed by a standard procedure employing polyclonal rabbit antibodies against human PTX3, as primary antibody (diluted 1:250, catalogue number P0496 purchased from Sigma Chemical); as second step, the sections were incubated with a peroxidase-conjugated polymer carrying an antibody against rabbit immunoglobulins (ChemMate Dako EnVision kit; Dako Cytomation). After washing out the excess of antibodies, a reaction product was developed by using the ChemMate diaminobenzidine as chromogen (Dako Cytomation). Negative control was made either by omitting the primary antibody or by using in the first step an isotype matched polyclonal antibody specific for HBcAg (Dako; diluted 1:200) (not shown). Sections were then counterstained with hemalume (Merck, Germany). The cells were judged as positive when the reaction product was well detectable at low magnification. Representative areas were imaged using a microscope equipped with a digital camera.

Immunofluorescence. Biopsy sections were prepared as described for immunohistochemistry (see above). Incubation with the primary antibody anti-PTX3 (1:200 in phosphate buffer saline supplemented with $0.1 \%$ Triton X-100 and $4 \%$ foetal calf serum, for $16 \mathrm{~h}$ in a humid chamber at $4^{\circ} \mathrm{C}$ ) was followed by a 1-h incubation with secondary antibodies conjugated with FITC (diluted 1:200 as above, for $1 \mathrm{~h}$ at room temperature in a humid chamber). Sections were also stained for actin, which marks the cell boarder, using a monoclonal antibody anti-human actin (diluted 1:200 as above; Sigma) followed by a TRITC-conjugated goat anti-mouse IgG, diluted 1:200 (Sigma). Excess of unbound antibody was removed by two washes with phosphate buffer saline. As negative control the cells were incubated with the secondary antibody alone. Stained sections were mounted with Slow-FAD (light antiFADE kit, Molecular Probes) and observed under an immunofluorescence microscope (Zeiss fluorescence microscope equipped with a digital camera). Each biopsy was tested at least 3 times.

PTX-3 protein. PTX3 was measured using a sandwich enzymelinked immunosorbent assay (ELISA) (13). In brief, 96-well ELISA plates (Nunc, Roskilde, Denmark) were coated with $100 \mathrm{ml}$ of anti-PTX3 monoclonal antibody (mAb) MNB4 in coating buffer (15 mM carbonate buffer $\mathrm{pH} 9.6$ ) and incubated overnight at $4^{\circ} \mathrm{C}$. After incubation, the plates were extensively washed 3 times with washing buffer (phosphate-buffered saline containing $0.05 \%$ Tween-20), and $300 \mathrm{ml}$ of $5 \%$ dry milk in washing buffer were added to block nonspecific binding sites. The plates were incubated for $2 \mathrm{~h}$ at room temperature and then washed 3 times with washing buffer. Purified human recombinant PTX3 standards (50 $\mu \mathrm{l})(75 \mathrm{pg} / \mathrm{ml}$ to $10 \mathrm{ng} / \mathrm{ml}$ ), or unknown plasma samples diluted in RPMI1640 medium (Seromed, Berlin, Germany) and 2\% bovine serum albumin (Sigma Chemicals), were added in triplicate to each well and incubated for $2 \mathrm{~h}$ at $37^{\circ} \mathrm{C}$. The plates were washed 5 times with washing buffer and $100 \mu$ l of biotinylated rabbit IgG anti-PTX3 diluted 1:2000 in washing buffer were added. The plates were incubated for $1 \mathrm{~h}$ at $37^{\circ} \mathrm{C}$, and then washed 5 times with $300 \mathrm{ml}$ of washing buffer. Streptavidinhorseradish peroxidase (100 $\mu \mathrm{l} /$ well) (Amdex, Copenhagen, Denmark) diluted 1:4000 was subsequently added and the plates incubated for $1 \mathrm{~h}$ at room temperature. After incubation, the plates were washed 5 times and $100 \mathrm{ml}$ of the chromogen substrate ABTS (Kirkegaard and Perry Laboratories, Gaithersburg, MD) were added. Plates were read after $15 \mathrm{~min}$ at $405 \mathrm{~nm}$ in an automatic ELISA reader.

Pro-inflammatory cytokine assay. Levels of TNF- $\alpha$, IL-6, and IL-1ß were determined in duplicate samples with a commercial enzyme-linked immunosorbent assay kit (R\&D Systems, Minneapolis, MN, USA), in accordance with the manufacturer's instructions. The lower limit of detection was $8 \mathrm{pg} / \mathrm{ml}$ for TNF- $\alpha, 3.5 \mathrm{pg} / \mathrm{ml}$ for IL-6 and $4.5 \mathrm{pg} / \mathrm{ml}$ for IL-1ß.

Statistical methods. Statistical analysis was performed using SPSS (version 10, SPSS Inc., Chicago, USA). Values are expressed as mean \pm standard deviation (SD). The distribution of males and females in the SP and MP groups was compared by Chi-square analysis. Differences among the groups were assessed by Student's t-test for two samples for normally distributed variables and Wilcoxon test for non-normally distributed variables. Spearman coefficients were calculated to determine the correlation among PTX3 and fibrinogen, CRP, PASI and cytokines. Significance tests were two-sided, and values $\mathrm{p}<0.05$ were considered significant.

\section{Results}

The results of our study show, on the one hand, inflammatory parameters between psoriatic patients and healthy controls, and, on the other, the changes between mild and severe psoriasis.

Immunohistochemistry and immunofluorescence analysis of $P T X 3$. In order to assess the presence of PTX3 protein and to define the cell types involved in PTX3 production, PTX3 expression was analysed in normal skin and in psoriatic lesion skin by immunohistochemistry analysis (Fig. 1a-d). Additionally, immunofluorescence analysis of PTX3 was performed in psoriatic lesion skin (Fig. 2). Fig. 1a shows the absence of PTX3 in vessel walls of normal skin, while Fig. 1b and c describe a strong PTX3 staining in severe psoriatic lesional skin. In particular, in psoriatic lesional skin, intense staining in dermal fibroblasts, endothelial cells and infiltrating of monocytes/macrophages was present; the nuclei were 

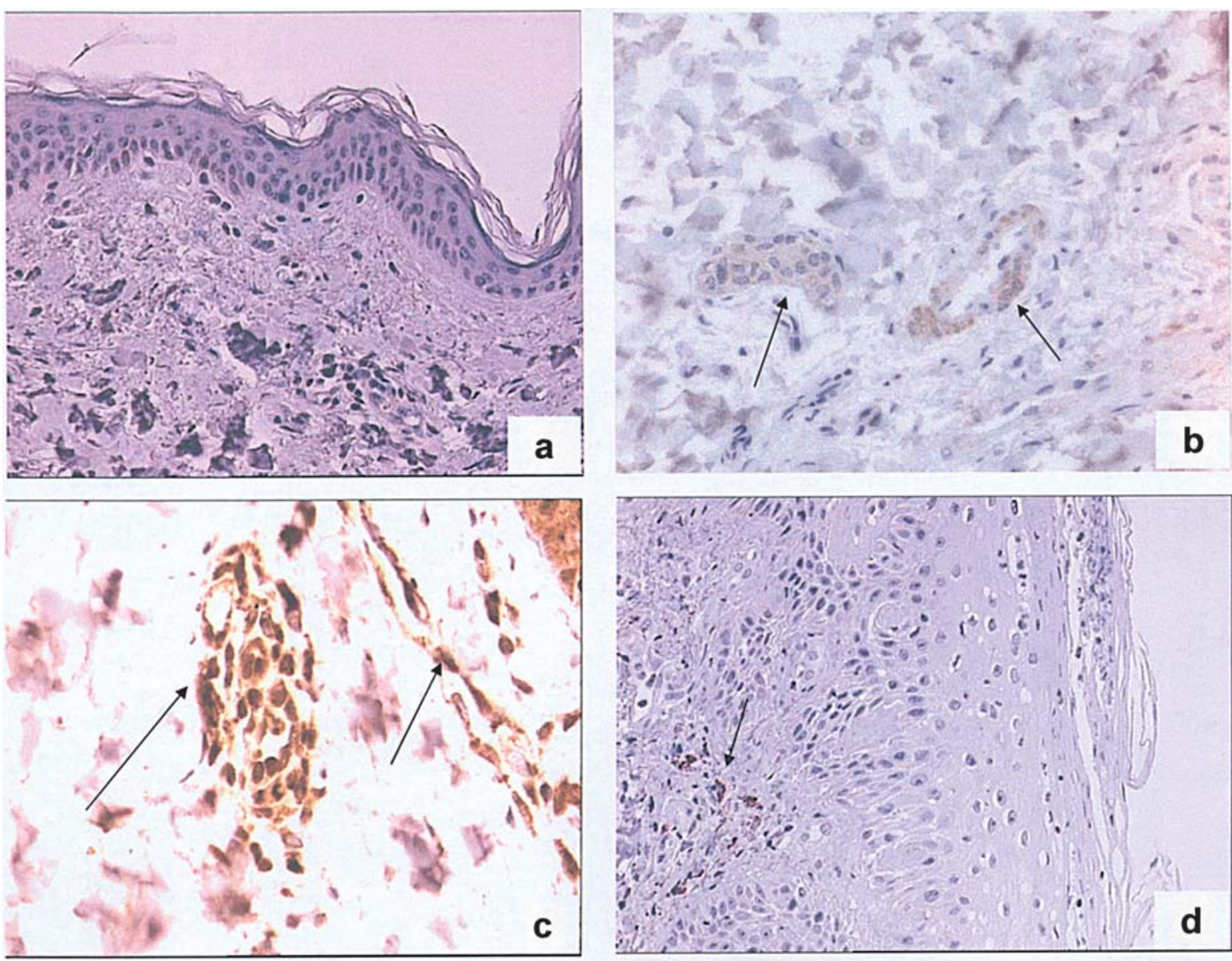

Figure 1. Expression of PTX3 by endothelial cells, macrophages and fibroblast. Section of human skin biopsy from normal skin shows the absence of PTX3 expression (a). Section of human skin biopsy from severe psoriasis shows the presence of expression of PTX3 in the endothelial cells (b) and macrophages (c). Section of human skin biopsy from mild psoriasis shows the presence of expression of PTX3 in macrophages (d).

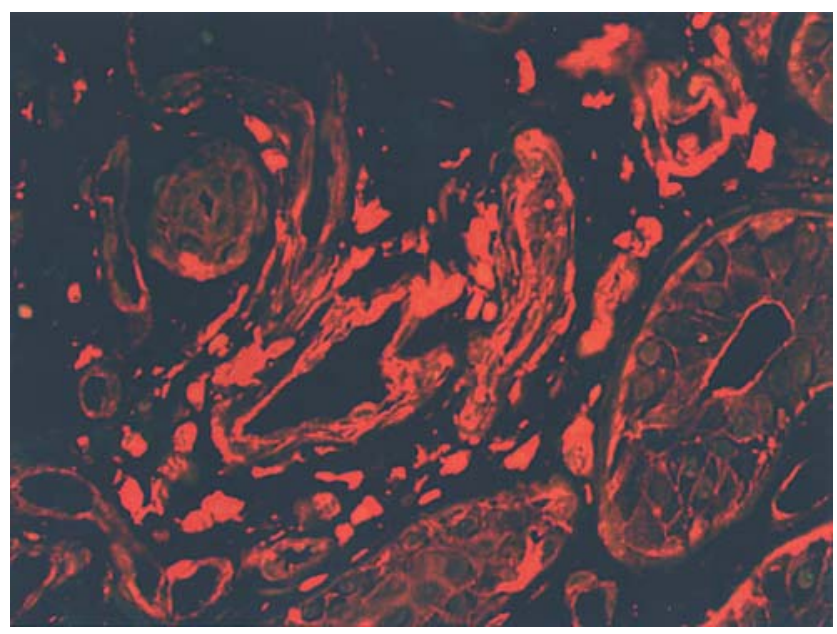

Figure 2. Immunofluorescence analysis of PTX3 in psoriatic lesion skin. Positivity was observed in endothelial cells and 'macrophage-like cells' in the dermal region.

constantly negative (Fig. 1c). These results were confirmed by immunofluorescence analysis of psoriatic lesional skin (Fig. 2). In mild psoriasis, a weak presence of PTX3 in vessel walls was evidenced by immunohistochemistry analysis and a few PTX3 positive cells (monocytes/macrophages) were detected in the dermis demonstrating a poor leucocyte infiltrate (Fig. 1d).

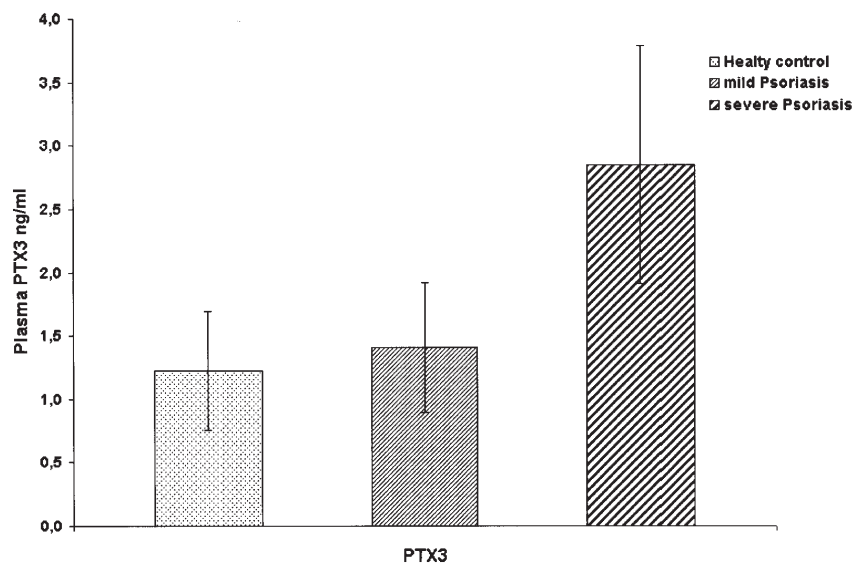

Figure 3. PTX3 plasma levels in mild and psoriatic patients.

PTX3 levels in plasma and in monocytic cultures. Fig. 3 shows PTX3 plasma levels in psoriatic patients and in healthy controls. Patients with severe psoriasis showed PTX3 plasma levels significantly higher than those of healthy controls $(\mathrm{p}<0.0001)$. Similarly, patients with severe psoriasis showed PTX3 plasma levels higher than those with mild psoriasis 


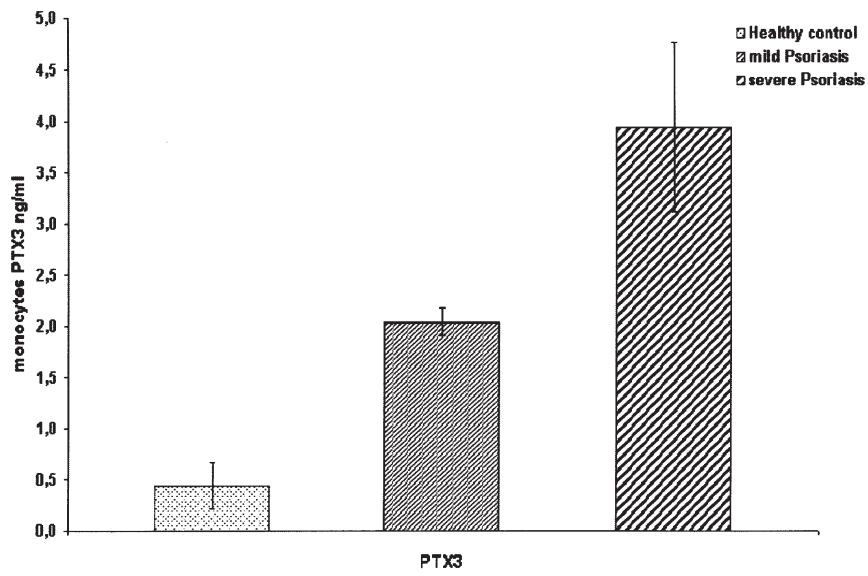

Figure 4. PTX3 levels in supernatant of monocytes cultures from mild and psoriatic patients.

$(\mathrm{p}<0.0001)$. While, no statistical significance were observed between PTX3 plasma levels of mild psoriasis patients and healthy controls (Fig. 3).

Fig. 4 shows the release of PTX3 in supernatant of purified monocytes from two groups of psoriatic patients (severe and mild psoriasis) and healthy controls. Monocytes from patients with severe psoriasis produced higher PTX3 levels when compared with those of mild psoriasis and healthy controls ( $\mathrm{p}=0.006, \mathrm{p}<0.0001$, respectively). In contrast to PTX3 plasma levels, significant differences in PTX3 production were found in mild psoriatic patients compared to healthy controls $(\mathrm{p}<0.0001)$ (Fig. 4).

CRP and fibrinogen levels. In addition to PTX3, CRP and fibrinogen levels were also studied as inflammatory markers. The mean serum level of CRP and plasma fibrinogen in severe, and mild psoriasis and the control groups are shown in Table II. Among group of patients with severe psoriasis, only 18 of $26(69.23 \%)$ showed increased serum levels of CRP. The difference of CRP serum levels between severe and mild psoriasis was statistically significant $(p<0.0001)$. No significant differences were observed between CRP serum levels in mild psoriasis patients and healthy controls. In the group of patients with severe psoriasis, only 15 of 26 $(34.09 \%)$ showed increased plasma levels of fibrinogen. Of note, 10 of these 15 patients were also affected by severe arthritis psoriasis. The difference of fibrinogen plasma levels between severe and mild psoriasis was statistically

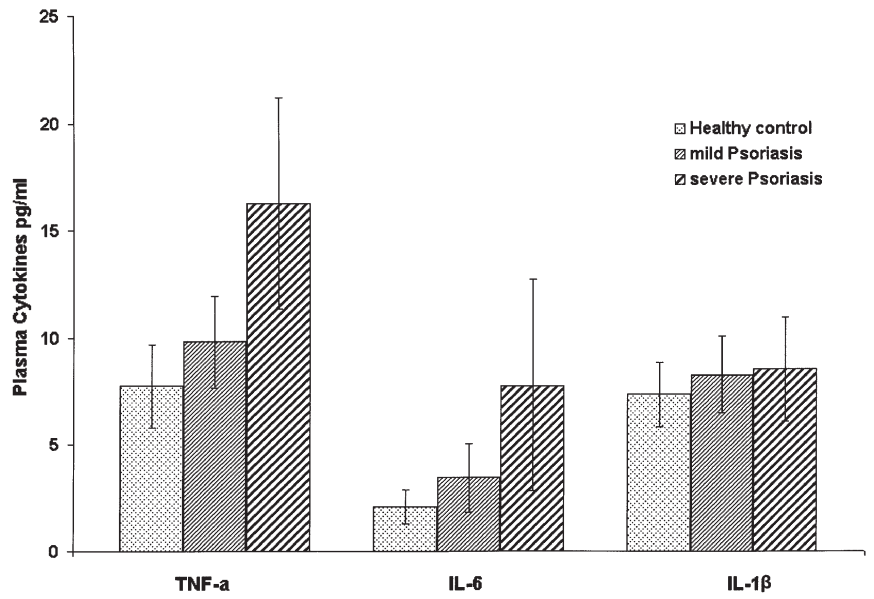

Figure 5. TNF- $\alpha$, IL-6 and IL-1ß levels in mild and psoriatic patients. TNF, tumor necrosis factor; IL, interleukin.

significant $(\mathrm{p}<0.0001)$. No significant differences were observed between CRP serum levels in mild psoriasis patients and healthy controls (Table II).

$I L-1 \beta, T N F-\alpha$ and IL-6 in plasma and in monocytic cultures. The mean value of TNF- $\alpha$ plasma levels was higher in mild psoriatic patients than healthy controls $(9.55 \pm 2.18 \mathrm{pg} / \mathrm{ml}$; $7.7 \pm 1.96 \mathrm{pg} / \mathrm{ml}$, respectively; $\mathrm{p}>0.05$ ) but lower than those with severe psoriasis $(16.3 \pm 1.96 \mathrm{pg} / \mathrm{ml}, \mathrm{p}<0.0001)$. The mean value of IL-6 plasma levels was higher in severe than in mild psoriasis patients and in healthy controls $(7.8 \pm 4.99 \mathrm{pg} / \mathrm{ml}$; $3.4 \pm 1.61 \mathrm{pg} / \mathrm{ml}, \mathrm{p}=0.004 ; 2.1 \pm 0.79 \mathrm{pg} / \mathrm{ml}, \mathrm{p}<0.001$, respectively). While, no differences were observed between mild psoriasis patients and healthy controls. IL- $1 \beta$ plasma levels were very low in both psoriatic groups and healthy controls $(7.4 \pm 1.51 \mathrm{pg} / \mathrm{ml} ; 8.3 \pm 1.8 \mathrm{pg} / \mathrm{ml} ; 8.5 \pm 2.42 \mathrm{pg} / \mathrm{ml}$, respectively) (Fig. 5).

In addition to plasma levels, we measured the concentration of TNF- $\alpha$ IL- 6 and IL- $1 \beta$ in the supernatant of purified monocytes from the same psoriatic patients. In severe psoriasis, cellular release of TNF- $\alpha(150 \pm 36.3 \mathrm{pg} / \mathrm{ml})$ and IL-6 $(184.73 \pm 64.11 \mathrm{pg} / \mathrm{ml})$ was statistically higher than in mild psoriatic group $(63 \pm 14.5 \mathrm{pg} / \mathrm{ml}$ and $30.5 \pm 11.08, \mathrm{p}<0.0001$, respectively) and healthy controls $(37 \pm 6.45 \mathrm{pg} / \mathrm{ml}$ and $24.6 \pm 9.28 \mathrm{pg} / \mathrm{ml}, \mathrm{p}<0.0001$, respectively). In mild psoriasis, only TNF- $\alpha$ levels were higher than healthy controls $(\mathrm{p}<0.001)$; IL-6 levels were similar than those from healthy controls. In

Table II. Inflammatory mediators in healthy controls and psoriatic patients.

\begin{tabular}{lccccrc}
\hline & $\begin{array}{c}\text { Healthy } \\
\text { controls (C) }\end{array}$ & $\begin{array}{c}\text { P-value } \\
\text { mP versus C }\end{array}$ & $\begin{array}{c}\text { mild } \\
\text { Psoriasis (mP) }\end{array}$ & $\begin{array}{c}\text { P-value } \\
\text { mP versus sP }\end{array}$ & $\begin{array}{c}\text { severe } \\
\text { Psoriasis (sP) }\end{array}$ & $\begin{array}{c}\text { P-value } \\
\text { sP versus C }\end{array}$ \\
\hline CRP mg/l & $<3$ & NS & $<3$ & $<0.0001$ & $7 \pm 4.93$ & $<0.0001$ \\
Fibrinogen mg/dl & $232.36 \pm 47.04$ & NS & $257.39 \pm 46.60$ & $<0.0001$ & $401.62 \pm 74.44$ & $<0.0001$ \\
PTX3 ng/ml & $1.22 \pm 0.47$ & NS & $1.4 \pm 0.5$ & $<0.0001$ & $2.84 \pm 0.94$ & $<0.0001$ \\
\hline
\end{tabular}

CRP, C-reactive protein; PTX3, pentraxin-3; P-value was calculated by Wilcoxon test; NS, not significant. 


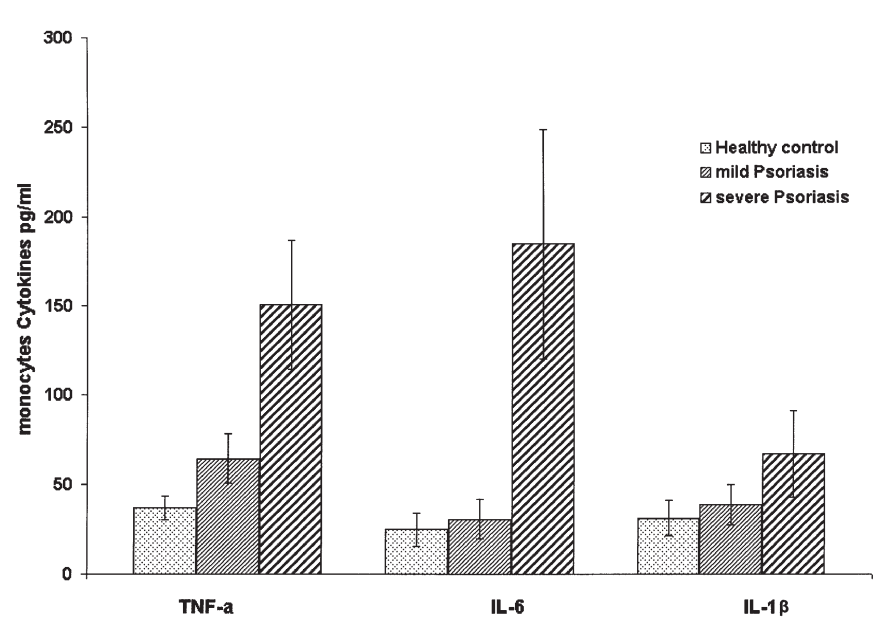

Figure 6. TNF- $\alpha$, IL- 6 and IL-1ß levels of supernatants of monocyte cultures from mild and psoriatic patients. TNF, tumor necrosis factor; IL, interleukin.
Table III. Correlation between PTX3 plasma levels and inflammatory markers in psoriatic patients.

\begin{tabular}{lcc}
\hline $\begin{array}{l}\text { PTX3 } \\
\text { versus }\end{array}$ & $\begin{array}{c}\text { mild Psoriasis } \\
\text { r-value }\end{array}$ & $\begin{array}{c}\text { severe Psoriasis } \\
\text { r-value }\end{array}$ \\
\hline CRP & $\mathrm{NS}$ & $\mathrm{NS}$ \\
Fibrinogen & $\mathrm{NS}$ & $0.47(\mathrm{p}=0.01)$ \\
TNF- $\alpha$ & $0.50(\mathrm{p}=0.03)$ & $0.54(\mathrm{p}=0.003)$ \\
IL-1ß & $\mathrm{NS}$ & $\mathrm{NS}$ \\
IL-6 & $\mathrm{NS}$ & $\mathrm{NS}$ \\
PASI score & $\mathrm{NS}$ & $0.63(\mathrm{p}=0.0006)$ \\
\hline
\end{tabular}

PTX3, pentraxin-3; CRP, $\mathrm{C}$ reactive protein; TNF- $\alpha$, tumor necrosis factor- $\alpha$; IL, interleukin; r-value was calculated by Spearman rank correlation test; NS, not significant.

are know to trigger relapses, including infection $(7,8)$, cutaneous trauma (9) and stress (6). Recent progress in the understanding of psoriasis has shown that the hyperplasia in psoriasis reflects an exaggerated response as innate and adaptive immunity (12). PTX3 belongs to the pentraxin family and participates in the acute phase response to injury, infection and trauma (31-33), factors that could, as previously indicated, trigger psoriatic disease. PTX3 is an important element of innate immunity, since it contributes to the regulation of inflammatory response. In human, CRP together with SAP are acute-phase proteins belonging to classical short pentraxins and, similar to PTX3, are activators of innate immunity and modulator of adaptive immunity (34). Short pentraxins are produced by the epatocytes in response to inflammatory cytokines (20). IL-1ß acts in synergy with IL-6 to enhance CRP and SAP gene induction $(21,22)$. PTX3 is a member of the pentraxin family, structurally related to, yet distinct from, classical pentraxins (19). In contrast, to short pentraxins, PTX3 is produced by dendritic cells, monocytes/macrophages, fibroblasts, endothelial cells and a variety of tissue cells upon exposure to inflammatory mediators such as LPS, IL- 13 and TNF- $\alpha$, but not IL-6 $(18,19)$. The importance of PTX3 in innate immune response and in inflammation has attracted our attention. Given the similarities and differences between PTX3 and CRP, we have studied PTX3 and its relationship with CRP, fibrinogen and the inflammatory cytokines in psoriasis.

This is the first study that investigated the role of PTX3 in psoriasis. In lesional skin, monocytic cultures and plasma from patients with psoriasis, a remarkable expression, production and release of PTX3 was found. In particular, we observed a strong PTX3 staining in fibroblasts, endothelial cells and monocytes/macrophages in severe psoriatic lesional skin. In sections of skin from patients with mild psoriasis only some endothelial cells and macrophages wre stained for PTX3. Specific vascular changes have been described in psoriasis skin (35). Epidermal hyperplasia, fibroblast, endothelial cell activation and leucocyte infiltration are features of psoriasis and are associated with a chronic inflammatory reaction. In contrast, in section of normal skin, quiescent endothelial cells cutaneous vasculature. It is characterized clinically by a relapsing and remitting course, many environmental factors
Psoriasis is a chronic inflammatory disease of the skin, characterized by increased proliferation and differentiation of keratinocytes, leucocytes infiltration and activation of the 
of vessels did not express PTX3. In severe psoriasis, immunohistochemistry results were confirmed by immunofluorescence analysis.

In addition, to immunohistochemical and immunofluorescence findings, we found also an increased production of PTX3 both in supernatant of purified monocytes and in plasma from patients with severe psoriasis. The significant correlation, found between cellular production and plasma levels of PTX3 in psoriasis, is a sign of cellular activation of monocytes/macrophages, the first cells to infiltrate the psoriatic lesion $(36,37)$. In mild psoriasis group, PTX3 production was also evident, even if lower than in severe psoriasis. We speculate that mild psoriatic patients with high production of PTX3 may evolve into severe psoriasis. This may be due to the activation of monocytes and was confirmed by initial leucocytes infiltration evidenced by immunostaining. Moreover, we found a positive correlation between PTX3 and disease activity of psoriasis indicated as PASI score. These findings suggest that PTX3 could be used as a further marker of disease activity of psoriasis. PTX3 levels were very low in serum and tissues of normal subjects but they rapidly increased in response to inflammatory stimulation in various diseases, such infections, autoimmune, and degenerative disorders $(38,39)$. Elevated levels of PTX3 have also been found in synovial fluid of RA patients, systemic scleroderma (SSc), and small vessel vasculitis (2729). In addition, among patients with active vasculitis, PTX3 expression in endothelial cells from biopsies of affected skin was demonstrated (29). Association of vasculitis and psoriasis has been reported in the literature $(40,41)$.

Immunostaining and production for PTX3 in our psoriatic samples is caused by both elevated inflammatory cellular response and activation of cells infiltrating lesional skin. Of note, this activation is induced by an increased proinflammatory cytokine production and release (42). TNF- $\alpha$, IL- 6 and IL-1ß are know to be the inflammatory cytokines involved in most inflammations. It was demonstrated that the production of PTX3 is induced by inflammatory mediators such as LPS, IL-1ß and TNF- $\alpha$ (18). These cytokines have been previously indicated as important modulators in the psoriasis process (42). Similarly to other authors, in severe psoriasis we found a significant correlation between PASI score and TNF- $\alpha$ and IL-6 levels in both supernatant of monocytes and plasma (14,43-46). Differently, no correlation was found for IL-1ß.

Our results are different from those of Okubo and Michiyuki (42) and Mizutani et al (47). The authors did not find any correlation between monocyte production of TNF- $\alpha$, IL-6 and IL-1ß and their plasma levels. These discrepancies may be due to the different geographic area of patients studied. In addition, patients unrolled in the present study had not been treated by topical or systemic therapy. In contrast, Okubo and Michiyuki (42) considered psoriatic patients treated with topical corticosteroids. Notably, in the present study some psoriatic patients were also complicated by arthritis. While, patients recruited by Mizutani and Michiyuki were affected by severe psoriasis but without arthritis (47).

Psoriasis arthritis is a heterogeneous disease with several articular patterns (48). Elevated levels of proinflammatory cytokines were observed in psoriasis arthritis (49-51). Our results emphasize the increased reactivity of monocytes in psoriatic patients both as antigen presenting cells and as active cells producing cytokines along with PTX3. Human monocytes produce PTX3 in response to inflammatory stimuli (18). In severe psoriasis we found a significant correlation between PTX3 and TNF- $\alpha$ both in monocytes and in plasma levels. Similar correlation was found in monocytes between PTX3 and IL-1ß, not in plasma levels. In contrast, we did not find any correlation between PTX3 and IL- 6 both in monocytes and in plasma levels. It has been demonstrated that the NFкB proximal site in human promoter is essential for induction by TNF- $\alpha$ and IL-1ß. No induction of the human promoter was observed with IL-6 (52).

In the present study, in addition to PTX3, we analyzed CRP and fibrinogen levels. Several authors suggested that CRP is a sensitive, but non-specific indicator of inflammation of various origins (22-24). Previous studies reported the existence of a significant correlation between PASI score and levels of CRP (15). Rocha-Pereira et al (53) also pointed out that, among inflammatory markers, only CRP could be a marker for worsening of psoriasis. Although, CRP serum levels were higher in psoriatic patients than controls, in the present study no correlation was observed between CRP levels and PASI score. These findings may be due to the fact that the distribution of CRP serum levels was different among the patients.

Although in some patients affected by severe psoriasis, the levels of PTX3 partially overlap with those of CRP, no correlation was found between PTX3 and CRP levels. Similarly, non-significant correlation has been observed in other clinical studies $(28,54)$. In agreement with previous studies, fibrinogen levels were increased in patients affected by psoriasis $(53,55)$, although we did not find any correlation with PASI score. In patients with severe psoriasis we observed a moderate correlation between plasma levels of PTX3 and fibrinogen. This correlation was previously found in active vasculitis (29).

In conclusion, in the present study we observed that a network of monocytes, proinflammatory cytokines, acute phase proteins collaborate to create an inflammatory environment in the skin that stimulates the proliferation of resident keratinocytes and endothelial cells, producing a pattern of tissue growth that is recognized as psoriasis. In particular, PTX3 may fulfil in lesional skin of psoriasis the same function that CRP exert in the circulation (19). Therefore, PTX3, from a clinical point of view, could be a new marker for monitoring the progression of psoriasis. Studies are in progress to evaluate the expression and production of PTX3 in psoriatic patients with biological therapy and to better clarify the role of PTX3 in psoriasis.

\section{References}

1. Chamian F and Krueger JG: Psoriasis vulgaris: an interplay of T lymphocytes, dendritic cells, and inflammatory cytokines in pathogenesis: Curr Opin Rheumatol 16: 331-337, 2004.

2. Bowcock AM and Krueger JG: Getting under the skin: the immunogenetics of psoriasis. Nat Rev Immunol 5: 699-711, 2005.

3. Lowes MA, Lew W and Krueger JG: Current concepts in the immunopathogenesis of psoriasis. Dermatol Clin 22: 349-369, 2004. 
4. Nickoloff BJ: The immunologic and genetic basis of psoriasis: Arch Dermatol 135: 1104-1110, 1999.

5. Sampogna F, Chren MM, Melchi CF, Pasquini P, Tabolli S and Abeni D: The Italian Multipurpose Psoriasis Research on Vital Experiences (Improve) Study Group: Age, gender, quality of life and psychological distress in patients hospitalized with psoriasis. Br J Dermatol 154: 325-331, 2006.

6. Picardi A, Mazzotti E, Gaetano P, Cattaruzza MS, Baliva G, Melchi CF, Biondi M and Pasquini P: Stress, social support, emotional regulation, and exacerbation of diffuse plaque psoriasis. Psychosomatics 46: 556-564, 2005.

7. Blok S, Vissers WH, van Duijnhoven M and van de Kerkhof PC: Aggravation of psoriasis by infections: a constitutional trait or a variable expression? Eur J Dermatol 14: 259-261, 2004.

8. Owen CM, Chalmers RJ and Griffiths CE: Streptococcal infection may make psoriasis worse but do antibiotics help? Br J Dermatol 151: 244-245, 2004.

9. Eyre RW and Krueger GG: Response to injury of skin involved and uninvolved with psoriasis, and its relation to disease activity: Koebner and 'reverse' Koebner reactions. Br J Dermatol 106: 153-159, 1982.

10. Bos JD, de Rie MA, Teunissen MB and Piskin G: Psoriasis: dysregulation of innate immunity. Br J Dermatol 152: 1098-1107, 2005.

11. Bowcock AM: The genetics of psoriasis and autoimmunity. Annu Rev Genomics Hum Genet 6: 93-122, 2005.

12. Bachelez H: Immunopathogenesis of psoriasis: recent insights on the role of adaptive and innate immunity. J Autoimmun 25: 69-73, 2005.

13. Yoshinaga Y, Higaki M, Terajima S, Ohkubo E, Nogita T, Miyasaka N and Kawashima M: Detection of inflammatory cytokines in psoriatic skin. Arch Dermatol Res 287: 158-164, 1995.

14. Bonifati C, Carducci M, Cordiali Fei P, Trento E, Sacerdoti G, Fazio M and Ameglio F: Correlated increases of tumour necrosis factor-alpha, interleukin-6 and granulocyte monocyte-colony stimulating factor levels in suction blister fluids and sera of psoriatic patients - relationships with disease severity. Clin Exp Dermatol 19: 383-387, 1994.

15. Laurent MR, Panayi GS and Shepherd P: Circulating immune complexes, serum immunoglobulins, and acute phase proteins in psoriasis and psoriatic arthritis. Ann Rheum Dis 40: 66-69, 1981.

16. Goodman AR, Cardozo T, Abagyan R, Altmeyer A, Wisniewski HG and Vilcek J: Long pentraxins: an emerging group of proteins with diverse functions. Cytokine Growth Factor Rev 7: 191-202, 1996.

17. Bottazzi B, Garlanda C, Salvatori G, Jeannin P, Manfredi A and Mantovani A: Pentraxins as a key component of innate immunity. Curr Opin Immunol 18: 10-15, 2006.

18. Mantovani A, Garlanda C and Bottazzi B: Pentraxin 3, a nonredundant soluble pattern recognition receptor involved in innate immunity Vaccine 21: S43-S47, 2003.

19. Bottazzi B, Vouret-CraviariV, Bastone A, De Gioia L, Peri G, Matteucci C, Spreafico F, Pausa M, D'Ettorre C, Gianazza E, Tagliabue A, Salmona M, Tedesco F, Introna M and Mantovani A: Multimer formation and ligand recognition by the long pentraxin PTX3-similarities and differences with the short pentraxins C-reactive protein and serum amyloid $\mathrm{P}$ component. J Biol Chem 272: 32817-32823, 1997.

20. Lin BF, Ku NO, Zahedi K, Whitehead AS and Mortensen RF: IL-1 and IL- 6 mediate increased production and synthesis by hepatocytes of acute-phase reactant mouse serum amyloid Pcomponent (SAP). Inflammation 14: 297-313, 1990.

21. Steel DM and Whitehead AS: The major acute phase reactants: C-reactive protein, serum amyloid $\mathrm{P}$ component and serum amyloid A protein. Immunol Today 15: 81-88, 1994.

22. Hirschfield GM and Pepys MB: C-reactive protein and cardiovascular disease: new insights from an old molecule. QJM 96: 793-807, 2003.

23. Dalla Vestra M, Mussap M, Gallina P, Bruseghin M, Saller A, Cernigoi AM, Plebani M and Fioretto P: Acute-phase markers of inflammation and glomerular structure in patients with type 2 diabetes. J Am Soc Nephrol 16: 78-82, 2005.

24. Arici M and Walls J: End-stage renal disease, atherosclerosis, and cardiovascular mortality: Is C-reactive protein the missing link? Kidney Int 59: 407-414, 2001

25. Fyrand O and Mellbye OJ: Deposition of fibrinogen (FRantigen) in skin diseases. III. Synovial joint membranes in psoriatic arthritis. Derm Venereol 57: 399-402, 1977.
26. Libra M, Signorelli SS, Bevelacqua Y, Navolanic PM, Bevelacqua V, Polesel J, Talamini R, Stivala F, Mazzarino MC and Malaponte G: Analysis of G(-174)C IL-6 polymorphism and plasma concentrations of inflammatory markers in patients with type 2 diabetes and peripheral arterial disease. J Clin Pathol 59: 211-215, 2006

27. Luchetti MM, Piccinini G, Mantovani A, Peri G, Matteucci C, Pomponio G, Fratini M, Fraticelli P, Sambo P, Di Loreto C, Doni $\mathrm{A}$, Introna $\mathrm{M}$ and Gabrielli $\mathrm{A}$ : Expression and production of the long pentraxin PTX3 in rheumatoid arthritis (RA) Clin Exp Immunol 119: 196-202, 2000

28. Luchetti MM, Sambo P, Majlingova P, Svegliati Baroni S, Peri G, Paroncini $\mathrm{P}$, Introna $\mathrm{M}$, Stoppacciaro A, Mantovani A and Gabrielli A: Scleroderma fibroblasts constitutively express the long pentraxin PTX3. Clin Exp Rheumatol 22: S66-S72, 2004.

29. Fazzini F, Peri G, Doni A, Dell'Antonio G, Dal Cin E, Bozzolo E, D'Auria F, Praderio L, Ciboddo G, Sabbadini MG, Manfredi AA, Mantovani A and Querini PR: PTX3 in small-vessel vasculitides: An independent indicator of disease activity produced at sites of inflammation. Arthritis Rheum 44: 28412850, 2001.

30. Böyum A: Isolation of mononuclear cells and granulocytes from human blood. Isolation of mononuclear cells by one centrifugation, and of granulocytes by combining centrifugation and sedimentation at $1 \mathrm{~g}$. Scand J Clin Lab Invest 97: 77-89, 1968.

31. Han B, Mura M, Andrade CF, Okutani D, dos Santos CC, Lodyga M, Keshavjee S, Matthay M and Liu M: TNFalphainduced long pentraxin PTX3 expression in human lung epithelial cells via JNK. J Immunol 175: 8303-8311, 2005.

32. Mairuhu AT, Peri G, Setiati TE, Hack CE, Koraka P, Soemantri A, Osterhaus AD, Brandjes DP, van der Meer JW, Mantovani A and van Gorp EC: Elevated plasma levels of the long pentraxin, pentraxin 3, in severe dengue virus infections. J Med Virol 76: 547-552, 2005.

33. Peri G, Introna M, Corradi D, Iacuitti G, Signorini S, Avanzini F, Pizzetti F, Maggioni AP, Moccetti T, Metra M, Cas LD, Ghezzi P, Sipe JD, Re G, Olivetti G, Mantovani A and Latini R: PTX3, A prototypical long pentraxin, is an early indicator of acute myocardial infarction in humans. Circulation 102: 636-641 2000 .

34. Du Clos TW and Mold C: C-reactive protein: an activator of innate immunity and a modulator of adaptive immunity. Immunol Res 30: 261-277, 2004.

35. Braverman IM and Yen A: Ultrastructure of the capillary loops in the dermal papillae of psoriasis. J Invest Dermatol 68: 53-60, 1977

36. Krueger GG, Jederberg WW, Ogden BE and Reese DL: Inflammatory and immune cell function in psoriasis: II. Monocyte function, lymphokine production. J Invest Dermatol 71: 195-201, 1978.

37. Brody I: Dermal and epidermal involvement in the evolution of acute eruptive guttate psoriasis vulgaris. J Invest Dermatol 82: 465-470, 1984.

38. Bussolati B, Peri G, Salvidio G, Verzola D, Mantovani A and Camusi G: The long pentraxin PTX3 is synthesized in IgA glomerulonephritis and activates mesangial cells. J Immunol 170: 1466-1472, 2003.

39. Garlanda C, Hirsch E, Bozza S, Salustri A, De Acetis M, Nota R, Maccagno A, Riva F, Bottazzi B, Peri G, et al: Non-redundant role of the long pentraxin PTX3 in anti-fungal innate immune response. Nature 420: 182-186, 2002.

40. Moreno JC, Velez A, Medina I, Valverde F, Fernandez-Roldan JC, Ocana MS, Espinosa M and Aljama P: Psoriasis, vasculitis and methotrexate. J Eur Acad Dermatol Venereol 17: 466-468, 2003.

41. Wong SS and Marks R: Cutaneous vasculitis in psoriasis. Acta Derm Venereol 74: 57-60, 1994.

42. Okubo Y and Koga M: Pheripheral blood monocytes in psoriatic patients overproduce cytokines. J Dermatol Sci 17: 223-232, 1998.

43. Arican O, Aral M, Sasmaz S and Ciragil P: Serum levels of TNF-alpha, IFN-gamma, IL-6, IL-8, IL-12, IL-17, and IL-18 in patients with active psoriasis and correlation with disease severity. Mediators Inflamm 24: 273-279, 2005.

44. Pietrzak A, Podhorecka M, Chodorowska G, Rolinski J, Kowal M, Junak-Bojarska A and Urban J: IL-6 and FAS (CD95) serum level in patients suffering from psoriasis and in relation to the lymphocyte subpopulations. Ann Univ Mariae Curie Sklodowska 59: 500-504, 2004. 
45. Abanmi A, Al Harthi F, Al Agla R, Khan HA and Tariq M: Serum levels of proinflammatory cytokines in psoriasis patients from Saudi Arabia. Int J Dermatol 44: 82-83, 2005.

46. Mussi A, Bonifati C, Carducci M, D'Agosto G, Pimpinelli F, D'Urso D, D'Auria L, Fazio M and Ameglio F: Serum TNFalpha levels correlate with disease severity and are reduced by effective therapy in plaque-type psoriasis. J Biol Regul Homeost Agents 11: 115-188, 1997.

47. Mizutani H, Ohmoto Y, Mizutani T, Murata M and Shimizu M: Role of increased production of monocytes TNF-alpha, IL-1beta and IL-6 in psoriasis: relation to focal infection, disease activity and responses to treatments. J Dermatol Sci 14: 145-153, 1997.

48. Gladman DD, Antoni C, Mease P, Clegg DO and Nash P: Psoriatic arthritis: epidemiology, clinical features, course, and outcome. Ann Rheum Dis 64: 14-17, 2005.

49. Yasumoto S, Imayama S and Hori Y: Increased serum level of interleukin- 6 in patients with psoriatic arthritis and thrombocytosis. J Dermatol 22: 718-722, 1995.

50. Spadaro A, Taccari E, Riccieri V, Sensi F, Sili Scavalli A and Zoppini A: Interleukin-6 and soluble interleukin-2-receptor in psoriatic arthritis: correlations with clinical and laboratory parameters. Clin Exp Rheumatol 14: 413-416 1996.
51. Mastroianni A, Minutilli E, Mussi A, Bordignon V, Trento E, D'Agosto G, Cordiali-Fei P and Berardesca E: Cytokine profiles during infliximab monotherapy in psoriatic arthritis. Br J Dermatol 153: 531-536, 2005.

52. Basile A, Sica A, d'Aniello E, Breviario F, Garrido G, Castellano M, Mantovani A and Introna M: Characterization of the promoter for the human long pentraxin PTX3. Role of NFkappaB in tumor necrosis factor-alpha and interleukin-1beta regulation. J Biol Chem 272: 8172-8178, 1997.

53. Rocha-Pereira P, Santos-Silva A, Rebelo I, Figueiredo A, Quintanilha A and Teixeira F: The inflammatory response in mild and in severe psoriasis. Br J Dermatol 150: 917-928, 2004.

54. Muller B, Peri G, Doni A, Torri V, Landmann R, Bottazzi B and Mantovani A: Circulating levels of the long pentraxin PTX3 correlate with severity of infection in critically ill patients Crit Care Med 29: 1404-1407, 2001.

55. Orem A, Deger O, Cimsit G and Bahadir S: Plasma polymorphonuclear leukocyte elastase levels and its relation to disease activity in psoriasis. Clin Chim Acta 264: 49-56, 1997. 